\title{
Quarantine for Zika Virus? Where is the Science?
}

\author{
Kristi L. Koenig, MD, FACEP, FIFEM
}

\section{ABSTRACT}

In January 2016, the World Health Organization warned that Zika virus is "spreading explosively" in the Americas and that up to 4 million infections could be present worldwide within a year. Soon thereafter, some politicians and authors publicly advocated for quarantine of travelers returning from regions where mosquitoes carrying Zika virus are prevalent. The public health tool of quarantine can be used to prevent the spread of infection by restricting the movement of persons who have been exposed to a deadly disease that can be transmitted from person to person before symptom onset. With $80 \%$ of Zika virus infections being asymptomatic, no rapid test being available to detect the virus, and primary transmission being via the bites of certain mosquitoes, application of quarantine in this setting is not scientifically sound or practically feasible. Rather, public health interventions should focus on preventing bites from infected mosquitoes, counseling pregnant women on the risks of fetal microcephaly and other birth defects, and identifying patients with signs and symptoms of Guillain-Barré syndrome. As was seen in the Ebola virus disease outbreak of 2014, non-evidence-based factors can influence policy decisions. Public health experts must ensure that policy makers are informed that quarantine is not a scientifically sound approach for the control of Zika virus. (Disaster Med Public Health Preparedness. 2016;10:704-706) Key Words: Zika, quarantine, Ebola, isolation, health policy

$\mathrm{O}$ n February 1, 2016, the Emergency Committee of the World Health Organization (WHO) declared the "cluster of microcephaly cases and other neurological disorders reported in Brazil, following a similar cluster in French Polynesia" to constitute a Public Health Emergency of International Concern. A statement by the WHO Director General noted that the committee advising her found "no public health justification for restrictions on travel or trade to prevent the spread of Zika virus." 1 Yet some authors and politicians encourage quarantine for travelers returning from areas where Zika virus is widespread. ${ }^{2-4}$ As our knowledge about this emerging infectious disease evolves, is this a scientifically defensible position?

Quarantine and isolation are both public health tools that involve physical separation and confinement of individuals to prevent disease transmission and protect the public health. Isolation is used for infected (symptomatic) people, whereas quarantine is for healthy (asymptomatic) people after exposure to a contagious disease that has the potential to be transmitted. Quarantine involves restriction of movement and infringement of civil liberties. The decision to enact quarantine should be based on the best evidence available and should not be driven by fear or political motivation., ${ }^{5,6}$ In general, in order for quarantine to be considered as a public health action, the disease in question must be transmissible from person to person, and this must be possible prior to symptom onset. ${ }^{7}$ Once symptoms occur, a person would be isolated rather than quarantined. In addition, the disease must have high morbidity and mortality. Zika virus does not meet these criteria. In addition, it is difficult to identify persons who are incubating the disease, because approximately $80 \%$ of infections are asymptomatic and there is no diagnostic test yet available at the local level to rapidly identify an infected person. This means that quarantine (used for asymptomatic persons early in a disease) would be virtually impossible.

We do not quarantine people for seasonal influenza (estimated to kill approximately 36,000 people per year in the United States alone) or malaria (with over 1 million deaths per year worldwide). Thus, even if there were a possibility of person-to-person transmission, why would we quarantine people after exposure to a virus that is usually asymptomatic or may manifest with mild flu-like symptoms, but is rarely deadly? The biggest concern about Zika virus is infection in pregnant women owing to its association with microcephaly. Quarantine would be unlikely to affect the incidence of microcephaly.

In prior times, the US president had to amend the executive order for quarantine each time a novel deadly contagious disease emerged, as was the case during the severe acute respiratory syndrome (SARS) epidemic. On July 31, 2014, the US government finally got it right, when the president amended the executive order for 
quarantine to stop being a list of diseases that had to be changed with each new emerging infection and instead described disease characteristics, eg, as being "severe acute respiratory syndromes" that are "capable of being transmitted person to person."

In addition to whether it makes scientific sense to quarantine according to disease characteristics, we must consider whether it is realistic and practical to evoke this limitation of movement and civil liberties. Would significant unintended negative consequences result from enacting quarantine "out of an abundance of caution" such as was seen in the case of Ebola virus disease when health care workers were deterred from traveling to West Africa to eradicate the disease at its source? In fact, the deleterious effects, including involuntary confinements and stigmatization of exposed persons, in the Ebola quarantine situation were so extreme that they resulted in a team of Yale law students filing legal action against the political decision-makers responsible. ${ }^{9}$

Furthermore, in open societies, it may be difficult to enforce quarantine authorities, especially if they are poorly understood and scientific evidence is lacking. Without a solid evidence base, it is difficult to provide the public with robust and sensible crisis and emergency risk communications so that they can understand the protective benefits of a quarantine action. This is the case with Zika virus, a vectorborne illness that is spread primarily by certain types of mosquitoes and that is not contagious from person to person in the classic sense. True, there is a potential that if a mosquito were to bite an infected person, and then bite an uninfected person, the virus could be spread. However, this would still be transmission of disease by the mosquito and not the person. Thus, the same protective measures to prevent mosquito bites would be more appropriate public health interventions than quarantine of the person. Others may argue that Zika can be spread by sexual contact and indeed reported cases of this type of spread are increasing. Certainly, if a male knew he was infected, he should take precautions and isolate. Nevertheless, while this documented "personto-person" spread is occurring, public health authorities have not previously advocated for quarantine (which is for asymptomatic persons) as an effective tool to inhibit transmission of a myriad of other sexually transmitted diseases. Furthermore, sexual transmission is not the usual mode.

Policies opposing mandatory quarantine for Ebola exist, ${ }^{10}$ eg, from the American College of Emergency Physicians, the Infectious Diseases Society of America, the Society for Healthcare Epidemiology of America, and the WHO, but none are yet published regarding Zika. In fact, Ebola is a much more deadly disease and it is highly infectious when patients are symptomatic, yet it still does not meet the criteria for quarantine as the statements of these authoritative bodies explain.

While we must monitor the evolving situation very closely, within the continental United States, the current risk of large outbreaks of Zika virus is thought to be low. This is due to the absence of circulating virus and the lack of possible reservoirs for the disease. Historical data show no high-level spread in the United States for other viruses transmitted by the same vectors, like dengue and chikungunya, despite large-scale global epidemics.

Nevertheless, some authorities have advocated screening of travelers returning from areas where there is risk of acquiring Zika infection. Even if it were effective, however, screening would be challenging owing to extensive international travel opportunities and the fact that the number of persons traveling to and from Zika-affected areas is extremely large, with multiple points of entry. Furthermore, the quarantine for patients identified via such screening would need to be implemented continuously because Zika is likely to become established in much of the world.

In conclusion, the current state of the science coupled with pragmatic considerations dictate that quarantine is not a useful or viable public health intervention to protect against Zika virus. Most importantly, the characteristics of the virus do not make it suitable for quarantine. Rather than focus on limiting contact of exposed persons with unexposed people, we should emphasize eliminating exposure to potentially infected mosquitoes in the first place and enhance efforts to control and eradicate these Zika virus-carrying mosquitoes. Additionally, scientists should consider the environmental impacts associated with vector control and explore other strategies to control disease spread. We must educate political decision-makers, health care providers, and the public, including women who are pregnant or contemplating pregnancy, about ways to protect themselves. Many nonmedical factors will continue to influence policy decisions if we do not demand informed leaders. We must advocate for outcomesbased research and scientific inquiry to inform health care leaders in protecting the public health. Politics should never trump science; rather, let the scientific experts make the decisions, not the politicians. Just say no to Zika quarantine- this is where we find the current state of the science!

\section{About the Authors}

Center for Disaster Medical Sciences, University of California at Irvine, Orange, California.

Correspondence and reprint requests to Kristi L. Koenig, MD, Center for Disaster Medical Sciences, Department of Emergency Medicine, UC Irvine Medical Center, 333 The City Boulevard West, Suite 640, Rt 128-01, Orange, CA 92868 (e-mail:kkoenig@uci.edu).

Published online: April 1, 2016.

\section{REFERENCES}

1. WHO statement on the first meeting of the International Health Regulations (2005) (IHR 2005) Emergency Committee on Zika virus and observed increase in neurological disorders and neonatal malformations. 
WHO website. http://www.who.int/mediacentre/news/statements/ 2016/1st-emergency-committee-zika/en/. Published February 1, 2016. Accessed Mar 6, 2016.

2. Republican U.S. presidential hopefuls say Zika quarantine may be needed. Reuters website. http://www.reuters.com/article/us-healthzika-usa-idUSKCNOVG07Z. Published February 7, 2016. Accessed Mar 6, 2016.

3. Savage says quarantine all travelers from Zika-infested nations. Michael Savage.com website. http://www.michaelsavage.wnd.com/2016/01/ new-york-times-bestselling-author-and-expert-in-epidemiology-dr-michaelsavage-explains-the-origins-of-viruses-and-their-impact-on-the-u-s/\#MgJqh 4qpE7S6c5qg.99. Published February 27, 2016. Accessed March 6, 2016.

4. Would quarantine slow Zika virus? The Columbus Dispatch. http://www. dispatch.com/content/stories/editorials/2016/02/22/1-quarantine-zika.html. Published February 22, 2016. Accessed March 6, 2016.

5. Koenig KL. Health care worker quarantine for Ebola: to eradicate the virus or alleviate fear? Ann Emerg Med. 2015;65:330-331. http://www.annemergmed.com/article/S0196-0644(14)01571-6/pdf. Accessed Mar 6, 2016.
6. Barbisch D, Koenig KL, Shih F-Y. Is there a case for quarantine? Perspectives from SARS to Ebola. Disaster Med Public Health Prep. 2015;9:547-553. doi:10.1017/dmp.2015.38.

7. Quarantine and Isolation Decision Tree. http://www.cdms.uci.edu/PDF/ Quarantine-and-Iso-Decison-tree.pdf. Accessed March 6, 2016.

8. Executive Order 12452-Revised list of quarantinable communicable diseases. National Archives website. https://www.whitehouse.gov/ the-press-office/2014/07/31/executive-order-revised-list-quarantinablecommunicable-diseases. Accessed March 6, 2016.

9. ACEP Ebola Expert Panel Consensus Statement on Restrictive Movement including Quarantine of Health Care Workers. http://www.acep. org/uploadedFiles/ACEP/practiceResources/issuesByCategory/publichealth/ ACEP\%20Ebola\%20Expert\%20Panel\%20Consensus\%20Statement.pdf. Accessed March 6, 2016

10. Fink S. Connecticut faces lawsuit over Ebola quarantine policies. New York Times. http://www.nytimes.com/2016/02/08/nyregion/connecticutfaces-lawsuit-over-ebola-quarantine-policies.html?_r $=0 . \quad$ Published February 7, 2016. Accessed March 6, 2016. 